\title{
Benign Pharyngeal Neoplasm
}

National Cancer Institute

\section{Source}

National Cancer Institute. Benign Pharyngeal Neoplasm. NCI Thesaurus. Code C3597.

A non-metastasizing neoplasm arising from the pharynx. Representative examples

include squamous papilloma and nasopharyngeal angiofibroma. 